\title{
LAST Line OF DEFEnSE: How Indiana CAN ENCOURAGE Naloxone AVAIlability DURING ITs OPIOID CRISIS
}

\author{
JOHN MILLIKAN*
}

\section{INTRODUCTION}

In fall 2009, Lawrence North sophomore Aaron Sims spent Friday nights as a promising young quarterback for his Indianapolis high school football team, bracing for his chance in the coming year to be the team's starter. ${ }^{1}$ Less than four years later, Sims was found dead in his bedroom next to a needle and a spoon with a shoelace choking his right arm. ${ }^{2}$ The story of Aaron Sims provides just one example of how quickly and drastically opioid abuse can destroy a life and just one example of how the epidemic of illicit drug use is sweeping across Indiana and the nation. Like many, Sims slipped into the dark world of opioid abuse by first getting his hands on a bottle of prescription painkiller drugs and progressed to stealing family members' pain relievers from their medicine cabinets. ${ }^{3}$ Eventually Sims became addicted to heroin, the drug that led to his overdose on Oct. 9, 2013. ${ }^{4}$

Heroin is one of dozens of drugs in the opioid family - a list that includes widely-prescribed pain relievers oxycodone, hydrocodone, codeine, morphine, and fentanyl. "Opioids are chemically related and interact with opioid receptors on nerve cells in the brain and nervous system to produce pleasurable effects and relieve pain," and "addiction is a primary, chronic, and relapsing brain disease characterized by an individual pathologically pursuing reward and/or relief by substance use and other behaviors." Overdoses are the leading cause of accidental death in the United States with 52,404 drug overdoses in 2015-a number that includes 20,101 overdose deaths from prescription pain relievers and 12,990 overdose deaths from heroin. ${ }^{7}$ In 2016, 757 people died from opioid overdoses in Indiana, ${ }^{8}$ a death rate fifty-two percent higher than the previous year

* J.D. Candidate, 2019, Indiana University Robert H. McKinney School of Law; B.A. 2009, Anderson University.

1. Matthew Tully, A Young Quarterback Lost to Heroin's Grip, InDIANAPOLIS STAR (Apr. 18, 2014), http://www.indystar.com/story/opinion/columnists/matthew-tully/2014/04/18/tullyyoung-quarterback-lost-heroins-grip/7871919/ [perma.cc/76LX-ZCTP].

2. $I d$.

3. Id.

4. $I d$.

5. Am. Soc'y of Addiction Med., Opioid Addiction: 2016 Facts \& Figures (2016), https://www.asam.org/docs/default-source/advocacy/opioid-addiction-disease-facts-figures.pdf [perma.cc/5JDR-MT7C] [hereinafter OpIOID AdDICTION: 2016 FACTS \& Figures].

6. $I d$.

7. Id.

8. INDIANA BY THE NUMBERS, IN.GOV, http://www.in.gov/recovery/1054.htm [perma.cc/9NEP-Z3FE] (last visited Nov. 27, 2017). 
and more than double from $2013 .{ }^{9}$

States around the country have addressed the opioid crisis in varying ways, including allocating funds for the purposes of rehabilitation, ${ }^{10}$ focusing treatment through buprenorphine, ${ }^{11}$ offering medication-assisted treatment ("MAT") while addicts are incarcerated, ${ }^{12}$ and passing laws to broaden the use of naloxone. ${ }^{13}$ Likewise, Indiana's legislature has enacted bills to fight opioid abuse, including laws to expand MAT to pregnant women and mothers, ${ }^{14}$ house and treat homeless individuals who have a drug addiction, ${ }^{15}$ provide mobile treatment units in underserved parts of the state ${ }^{16}$ ease requirements for needle exchanges,${ }^{17}$ limit opioid prescribing, ${ }^{18}$ and provide treatment to nonviolent drug offenders. ${ }^{19}$ In the wake of Sims' heroin overdose death, the Indiana legislature also passed "Aaron's Law," which allows individuals to obtain a prescription for naloxone if they believe someone they know is at risk of an opioid overdose. ${ }^{20}$ Naloxone, commonly referred to as the brand name Narcan, is a prescription medication that effectively and reliably reverses the effects of an opioid overdose and allows the overdose victim time to seek treatment. ${ }^{21}$ Before Aaron's Law, Indiana limited the use of naloxone to emergency medical professionals. ${ }^{22}$ But now laypersons can

9. Eric Holcomb, Why I am Focusing on the Opioid Crisis, Indianapolis StaR (Sept. 30, 2017), http://www.indystar.com/story/news/2017/09/30/gov-holcomb-opioid-opioids-opioidaddiction-opioid-epidemic-opioid-withdrawal-opioid-overdose-pain-p/716337001/ [perma.cc/6ST8VDQX].

10. Jackie Borchardt, Ohio Democrats Want to Fight Opioid Crisis with $\$ 200$ Million from State's Rainy Day Fund, Cleveland Plain DeALER (May 17, 2017), http://www.cleveland.com/ metro/index.ssf/2017/05/ohio_democrats_want_to_fight_o.html [perma.cc/5G3X-XT2H].

11. IMS InSt. For HeAlthCARE Informatics, Use of Opioid ReCOVERy MEDiCATIONS: Recent Evidence on State Level Buprenorphine Use and Payment Types (2016), http://www.imshealth.com/files/web/IMSH\%20Institute/Reports/Healthcare\%20Briefs/IIHI_Us e_of_Opioid_Recovery_Medications.pdf [perma.cc/55RT-FXNG].

12. Andrew Joseph, One State Takes a Novel Approach to Opioid Addiction: Access to Treatment for All Inmates, STAT (Aug. 3, 2017), https://www.statnews.com/2017/08/03/opioidtreatment-prisons/ [perma.cc/3NVE-C3AP].

13. Katie Kull, Missouri House Passes Bill Giving Immunity for Overdose Help, AssocIATED Press (May 26, 2017), https://www.apnews.com/1 eb1 f89ef706499f9e787e0b52bb8f3b [perma.cc/DW2Q-44HB].

14. IND. CODE $\S 12-7-2-128.7$ (2017).

15. Id. $\S 5-20-9$.

16. Id. $\S 12-7-2-1.4$.

17. Id. $\S 16-41-7.5-4$.

18. Id. $\S 25-1-9.7$.

19. Id. § 33-33-2-46.

20. Id. § 16-42-27-2.

21. James M. Chamberlain \& Bruce L. Klein, A Comprehensive Review of Naloxone for the Emergency Physician, 12 Am. J. EMERgency Med. 650, 650 (1994).

22. Christin Nance Lazerus, Indiana Expanding Access to Heroin Overdose Antidote, CHI. TRIB. (June 5, 2015), http://www.chicagotribune.com/suburbs/post-tribune/news/ct-ptb-naloxone- 
obtain a prescription and administer the drug. ${ }^{23}$

This Note argues that although Indiana took a step in the right direction in 2015 by passing Aaron's Law, the state must continue to break down remaining barriers between opioid overdose victims and access to naloxone. Specifically, Indiana should pass laws providing criminal and professional immunity to prescribers, dispensers, and laypersons, and federal law should permit naloxone to be purchased as an over-the-counter drug. Part I of this Note explains the history of opioids and how they emerged as a major contributor to addiction and overdose deaths in the United States. Part II examines the different ways the opioid crisis is being addressed in the United States, focusing on the use of naloxone but also explaining methadone and buprenorphine treatments, counseling, and MAT. Part II also discusses the arguments against increased access to naloxone, including the misguided belief that expanding the availability of it will provide opioid abusers an easy antidote from overdosing and will encourage and enable them to continue to take drugs at dangerous levels. Part III explains the current naloxone laws in Indiana compared to those of other states and at the federal level. Part IV argues that the most effective way to expand the availability of naloxone is for the Indiana legislature to pass laws that provide criminal and professional immunity to prescribers, dispensers, and laypersons and for the U.S. Food and Drug Administration ("FDA") to reschedule naloxone as an over-the-counter drug.

\section{HISTORY OF OPIOIDS IN INDIANA AND THE UNITED STATES}

\section{A. A Centuries-Old Remedy for Pain}

Opium is a powdery substance obtained from the seedpod of the opium poppy and has been used for thousands of years to form opioids, which relieve pain and suffering. ${ }^{24}$ For most of its history, opium was used primarily in the Middle East, but in 1806 the morphine alkaloid was identified, ushering in the beginning of the pharmacological production of opioid drugs. ${ }^{25}$ Use of opioid drugs became ordinary in the nineteenth century, and individuals used the drugs to treat non-medical issues, such as boredom, and ailments like colic and diarrhea. ${ }^{26}$ But as the use of opioids became more commonplace, attempts to legislate its use emerged throughout the United States, beginning in 1875 when the city of San Francisco criminalized smoking opium outside of "opium dens." 27 Opioid legislation finally took to the national stage when Congress passed the

overdose-antidote-st-0530-20150605-story.html [perma.cc/KM54-HJ8X].

23. IND. CODE $§ 16-42-27-2$.

24. Jane C. Ballantyne \& Jianren Mao, Opioid Therapy for Chronic Pain, 349 NEw Eng. J. MED. 1943, 1943 (2003).

25. Id.

26. Id.

27. Patricia Morgan, The Legislation of Drug Law: Economic Crisis and Social Control, 8 J. DRUG ISSUES 53, 59 (1978). 
Harrison Narcotics Act of 1914, regulating opioid use by imposing "a special tax upon all persons who produce, import, manufacture, compound, deal in, dispense, sell, distribute, or give away opium or coca leaves, their salts, derivatives, or preparations, and for other purposes. ${ }^{28}$

Legislative action and a number of U.S. Supreme Court rulings in the decades following the Harrison Narcotics Act further regulated opioid use to the point that, by the 1940s, opioids could only be "prescribed by physicians according to strict regulatory controls." 29 Physicians were initially reluctant to prescribe opioids because of liability for doing so inappropriately, but advocates for pain control helped opioids become socially and medically accepted and eventually embraced by the end of the twentieth century. ${ }^{30}$ Still, a minority in the medical community "argue that opioids are only marginally useful in the treatment of chronic pain, have a minimal effect on functioning, and may even worsen the outcome," but most physicians agree that opioids are an effective way to treat chronic pain. ${ }^{31}$

Generally, non-terminal patients suffering from chronic pain achieve satisfactory results and have minimal risk of addiction when using a stable dose of opioids. ${ }^{32}$ Physicians commonly prescribe opioids because of the wide-held belief among their peers that opioids are a necessary tool to combat chronic pain, which is defined as pain with a duration of more than three months ${ }^{33}$ that can significantly affect quality of life by causing "impairment of physical and psychological health and performance of social responsibilities, including work and family life." ${ }^{\prime 3}$ A study conducted by the Centers for Disease Control and Prevention ("CDC") from 2000 to 2010 found that "an estimated 1 out of 5 patients with non-cancer pain or pain-related diagnoses are prescribed opioids in office-based settings, ${ }^{, 35}$ and a 2017 study conducted by the National Institute of Drug Abuse revealed that one in three Americans used prescription opioid painkillers in $2015 .^{36}$

Non-opioid alternatives to relieve chronic pain include options such as anticonvulsants, serotonin and norepinephrine reuptake inhibitors, tricyclic

28. Harrison Narcotics Act of 1914, Pub. L. No. 63-223, 38 Stat. 785 (1914) (repealed 1970).

29. Ballantyne \& Mao, supra note 24, at 1943.

30. Id.

31. Id. at $1943-44$.

32. Id.

33. Bernard Bannwarth, Risk-Benefit Assessment of Opioids in Chronic Noncancer Pain, 21 DRUG SAFETY 283, 284 (1999).

34. Laxmaiah Manchikanti et al., Opioids in Chronic Noncancer Pain, 10 EXPERT REV. NEUROTHERAPEUTICS 775, 775 (2010).

35. Prescribing Data, Ctrs. for Disease Control \& Prevention (last updated Aug. 30, 2017), https:/www.cdc.gov/drugoverdose/data/prescribing.html [perma.cc/DEM4-YEF7].

36. Corky Siemaszko, One in Three Americans Took Prescription Opioid Painkillers in 2015, Survey Says, NBC NEws (July 31, 2017), https:/www.nbcnews.com/storyline/americas-heroinepidemic/one-three-americans-took-prescription-opioid-painkillers-2015-survey-says-n788246 [perma.cc/F5D3-UAZ9]. 
antidepressants, over-the-counter medications, and topical nonsteroidal antiinflammatory drugs ("NSAIDs"). ${ }^{37}$ Non-opioid pain management methods being investigated include endomorphins, spinal cord stimulation, and psychotherapy. ${ }^{38}$ Medicinal marijuana is also considered an option for pain management. ${ }^{39}$ However, since "both clinical trials and clinical practice offer good evidence that non-opioid analgesics do not provide satisfactory pain relief," opioid painkillers remain the most effective treatment option for most patients with chronic pain. ${ }^{40}$

\section{B. From Medication to Addiction}

Opioids, including commonly prescribed drugs OxyContin and Vicodin, attach to receptors in the brain when ingested and "reduce the perception of pain and can produce a sense of well-being." ${ }^{41}$ Because of the euphoric effects of opioids and their effectiveness in relieving pain, patients have a tendency to use the drugs repeatedly over time, which induces tolerance. ${ }^{42}$ "Tolerance occurs when the person no longer responds to the drug as strongly as he or she did at first, thus necessitating a higher dose to achieve the same effect." ${ }^{\text {"43 }}$ High tolerance leads to high opioid consumption, which can produce an overdose. ${ }^{44}$ Because opioids affect brain receptors that are responsible for breathing, an overdose victim becomes unresponsive to stimulation and breathing becomes inadequate, which causes lips and fingers to turn blue - the common first signs of an opioid overdose. $^{45}$ Eventually, lack of oxygen affects vital organs throughout the body_including the brain and heart-leading to unconsciousness, coma, or death. ${ }^{46}$

One study suggested that opioids could kill nearly 500,000 Americans in the

37. Lauren B. McKnight, Pain Management: Non-Opioid Medications, Pharmacy Times (July 22, 2013), http://www.pharmacytimes.com/publications/health-system-edition/2013/ july2013/pain-management-non-opioid-medications [perma.cc/WDT5-LYTA].

38. Crystal Wong, Non-Opioid Drugs and Methods for Pain Control, Psychiatry ADVISOR (Oct. 14, 2016), http://www.psychiatryadvisor.com/news/non-opioid-drugs-and-methods-for-paincontrol/article/548181/ [perma.cc/YS4J-YCM4].

39. Claire Frezza, Medical Marijuana: A Drug Without a Medical Model, 101 Geo. L.J. 1117,1122 (2013).

40. Bannwarth, supra note 33, at 284.

41. Nora D. Volkow, America's Addiction to Opioids: Heroin and Prescription Drug Abuse, NAT'L INST. DRUG ABUSE, https://www.drugabuse.gov/about-nida/legislative-activities/testimonyto-congress/2016/americas-addiction-to-opioids-heroin-prescription-drug-abuse [perma.cc/2Y7ZLPLF] (last visited Nov. 27, 2017).

42. Id.

43. Id.

44. Mass. Dep't of Pub. Health, Opioid Overdose Education and Naloxone DistribUTION (2016), http://www.mass.gov/eohhs/docs/dph/substance-abuse/core-competenciesfor-naloxone-pilot-participants.pdf [perma.cc/8WUT-Y2GD].

45. Id.

46. Id. 
next decade, ${ }^{47}$ and opioid addiction affects all races, sexes, ages, and income brackets. More than 120,000 minors from age twelve to seventeen years old were addicted to prescription pain relievers in 2015, and the rate of prescription use among minors nearly doubled from 1994 to $2007 . .^{48}$ Older patients also struggle with addiction to opioids. Those aged forty-five to sixty-four made up forty-four percent of overdose deaths in America from 2013 to 2014, and "the proportion of adults 50 and older seeking treatment for opioid addiction has increased dramatically in recent decades." ${ }^{49}$ Opioid overdose death victims are predominantly white non-Hispanics, but the also black and Hispanic populations suffered a substantial number of deaths. ${ }^{50}$ Heroin use in the United States has increased among "all income levels," with those making between \$20,000 and $\$ 49,000$ a year seeing a seventy-seven percent rise in heroin use, compared to around a sixty percent rise in the income brackets below and above that range. ${ }^{51}$ Statistics suggest that "women may become dependent on prescription pain relievers more quickly than men," and nearly 50,000 women died of prescription opioid overdoses between 1999 and $2010 .^{52}$ However, men are even more likely to die from prescription opioid overdose. ${ }^{53}$

A recent study by the CDC found that addiction to prescription opioids can happen in a matter of days: "Even a one-day opioid prescription carried a 6 percent risk of use at one year later and a 2.9 percent risk of use at three years later." ${ }^{54}$ Dependence spikes five days after the initial ingestion of prescription opioids, with another large spike after continuing use for one month. ${ }^{55}$

47. Max Blau, STAT Forecast: Opioids Could Kill Nearly 500,000 Americans in the Next Decade, STAT (June 27, 2017), https://www.statnews.com/2017/06/27/opioid-deaths-forecast/ [perma.cc/662V-V3QU].

48. OpIOID AdDiction: 2016 FACTS \& FigURES, supra note 5.

49. Laura Landro, Opioid Use Soars Among Middle Aged and Elderly, Wall Street J. (Apr. 23, 2017), https://www.wsj.com/articles/opiod-use-soars-among-middle-aged-and-elderly1492999801 [perma.cc/JBC9-FF7D].

50. Opioid Overdose Deaths by Race/Ethnicity, Henry J. KAISER FAM. Found., https://www.kff.org/other/state-indicator/opioid-overdose-deaths-by-raceethnicity/ ?dataView $=0 \&$ currentTimeframe $=0$ \&sortModel $=\% 7 \mathrm{~B} \% 22$ colId $\% 22: \% 22$ Location $\% 22, \% 22$ sor $\mathrm{t} \% 22: \% 22$ asc\%22\%7D [perma.cc/SEU7-ZC84] (last visited Nov. 27, 2017). In fact, 2015, more than 27,000 white non-Hispanic individuals died from opioid overdoses, and more than 5,000 black and Hispanic individuals died from such overdoses.

51. Today's Heroin Epidemic, CTRS. FOR DiseAse CONTROL \& Prevention, https://www.cdc.gov/vitalsigns/heroin/ [perma.cc/4LRV-6HDS] (last updated July 27, 2015).

52. OpIOID AdDICTION: 2016 FACTS \& FigURES, supra note 5.

53. Prescription Opioid Overdose Data, Ctrs. for Disease Control \& Prevention, https://www.cdc.gov/drugoverdose/data/overdose.html [perma.cc/U7CJ-CPBL] (last updated Aug. 1, 2017).

54. Jessica Wapner, CDC Study Finds Opioid Dependency Begins Within a Few Days of Initial Use, NEwSwEEK (Mar. 22, 2017), http://www.newsweek.com/cdc-opiate-addiction-572498 [perma.cc/FGG5-HQS9].

55. Id. 
Dependency is defined as "a state of adaptation that is manifested by a drug class specific withdrawal syndrome that can be produced by abrupt cessation, rapid dose reduction, decreasing blood level of the drug, and/or administration of an antagonist" and is an expected result of prolonged opioid use; however "physical dependence may develop after the use of a dependency-producing drug for only $48 \mathrm{~h}$ [ours]. " ${ }^{, 56}$ Fatal overdose is a serious risk for those who are addicted to opioids, and while some are merely victims of accidentally taking too much of their prescribed opioids, ${ }^{57}$ others either illegally obtain the drugs ${ }^{58}$ or intentionally misuse their prescribed painkillers in a nontherapeutic way. ${ }^{59}$ Fatal overdoses can be especially dangerous for those who have been incarcerated and then return to the street with a lower tolerance to the drug than when they entered prison, ${ }^{60}$ as well as individuals who are attempting to curb their addiction through a rehabilitation program and overdose during a relapse because of their change in tolerance. $^{61}$

Even though narcotics have been restricted for more than a century throughout the country, the epidemic did not become widespread until OxyContin hit the market in $1996 .{ }^{62}$ A year before OxyContin was introduced to the American public, the number of painkiller prescriptions filled annually in the United States was 87 million. ${ }^{63}$ By 2012, the number of annual painkiller prescriptions filled in the United States peaked at 259 million. ${ }^{64}$ The most recent data provided by the U.S. Department of Health and Human Services shows that each day in the United States, an average of more than 650,000 opioid prescriptions are dispensed, 3,900 people initiate nonmedical use of prescription opioids, 580 people initiate heroin use, and 78 people die from an opioid-related

56. Jette Højsted \& Per Sjøgren, Addiction to Opioids in Chronic Pain Patients: A Literature Review, 11 Eur. J. PAIN 490, 491 (2007).

57. Catherine Sanford, Deaths from Unintentional Drug Overdoses in North Carolina, 1997-2001: A DHHS Investigation into Unintentional Poisoning-Related DEATHS (2002).

58. Andrew Rosenblum et al., Prescription Opioid Abuse Among Enrollees into Methadone Maintenance Treatment, 90 DRUG \& Alcohol DePendence 64, 67 (2007).

59. Theodore J. Cicero et al., Trends in Abuse of OxyContin and Other Opioid Analgesics in the United States: 2002-2004, 6 J. PAIN 662, 668 (2005).

60. Ingrid A. Binswanger et al., Release from Prison-A High Risk of Death for Former Inmates, 356 New ENG. J. MED. 157, 160-63 (2007).

61. Can You Overdose on Suboxone?, Am. Addiction CTRs., https://americanaddictioncenters.org/suboxone/can-you-overdose/ [perma.cc/WD4R-HXGG]. (last visited Nov. 27, 2017).

62. Donia Moghe, Opioid History: From 'Wonder Drug' to Abuse Epidemic, CNN (Oct. 4, 2016), http://www.cnn.com/2016/05/12/health/opioid-addiction-history/index.html [perma.cc/B84V-PF7D].

63. Volkow, supra note 41.

64. Nat'l SAfety Council, Prescription Nation 2016: AdDressing America's Drug EPIDEMIC (2016), http://www.nsc.org/RxDrugOverdoseDocuments/Prescription-Nation-2016American-Drug-Epidemic.pdf [perma.cc/DUQ5-BGMV]. 
overdose. $^{65}$

\section{Indiana at the Heart of the Crisis}

The United States adopted its first anti-narcotics law in 1914 with the Harrison Act, ${ }^{66}$ and Indiana enacted its own state law against the possession of narcotics in 1935 with the Uniform Narcotic Drug Act. ${ }^{67}$ Before 2000, the mortality rate per year in Indiana for overdose deaths stayed below 5.0 per 100,000 people, but the rate has since skyrocketed and is now the leading cause of accidental death in the state. ${ }^{68}$ Indiana ranked seventeenth in the nation in overdose deaths in 2015 with 19.5 deaths per 100,000 people, ${ }^{69}$ and although "overdose deaths due to prescription drugs have leveled off in some states, overdose deaths in Indiana continue to rise." "70 Twenty-six percent of Indiana high school seniors reported using prescription drugs without a prescription, and 12.2 percent of Indiana adults aged twenty-five and younger abuse prescription drugs, compared to the national average of 9.5 percent. ${ }^{71}$ Opioids are the primary reason Indiana residents are 8.0 percentage points more likely than the national average to enter a drug treatment program. ${ }^{72}$

Opioid abuse in Indiana also affects those who do not use opioids but who are related to abusers. An increasing number of children enter the welfare system, "primarily because of parental substance abuse." I3 In Indiana, 657 infants were born in 2014 with Neonatal Abstinence Syndrome, "a condition that can result in increased irritability, hypertonia (spasticity), tremors, difficulty eating, vomiting, watery stools, seizures and respiratory distress" and requires lengthy hospitalization. ${ }^{74}$ In 2010, non-fatal poisonings accounted for 641,940 emergency

65. U.S. Dep't of Health \& Human Servs., The Opioid Epidemic: By the Numbers (2016), https://www.hhs.gov/sites/default/files/Factsheet-opioids-061516.pdf [perma.cc/99JGD6DC].

66. Harrison Narcotics Act of 1914, Pub. L. No. 63-223, 38 Stat. 785 (1914) (repealed 1970).

67. McGowan v. State, 296 N.E.2d 667, 673 (Ind. Ct. App. 1973) (explaining that the 1935 Narcotic Act makes it unlawful "for any person to manufacture, possess, have under his control, sell, prescribe, administer, dispense, compound or use any narcotic drug or drugs except as authorized in the laws of the United States or the state of Indiana, or for any person to be found in a public place under the influence of narcotic drugs.")

68. Joan Duwve et Al., Ind. Univ. Richard M. Fairbanks Sch. of Pub. Health, Report ON THE TOll of Opioid USE IN INDiAnA AND MARION COUNTy 53 (2016), https://www. inphilanthropy.org/sites/default/files/Richard\%20M.\%20Fairbanks\%20Opioid\%20Report\%20S eptember\%202016.pdf [perma.cc/VS3E-3W4C].

69. Drug Overdose Death Data, Ctrs. For Disease Control \& Prevention, https://www. cdc.gov/drugoverdose/data/statedeaths.html [perma.cc/B8AL-HDV4] (last updated Dec. 16, 2016).

70. Duwve ET AL., supra note 68 at 16.

71. Id. at 18 .

72. Id. at 22 .

73. Id. at 6 .

74. Id. 
room visits in Indiana, and 90 percent of those poisonings were because of drug abuse, burdening "the ability of hospitals to deliver timely care." " Fifty-three percent of those incarcerated in Indiana's jails and prisons are "diagnosed with a substance use disorder," and of those in the state who are sent to prison multiple times, seventy-five percent abuse drugs. ${ }^{76}$

\section{ADDRESSING THE OPIOID EPIDEMIC}

\section{A. Variety of Treatments for Opioid Addiction}

Naloxone is a tool used to sustain the life of an opioid abuser who would otherwise be moments away from death, and there are treatments available for those addicted to opioids that are effective in rehabilitation and give overdose survivors revived by naloxone a path to recovery. The most common methods of opioid addiction treatment are through methadone and buprenorphine-a pair of therapeutic opioids injected in drug users as replacement therapy. ${ }^{77}$ Methadone and buprenorphine are also the most common drugs prescribed in conjunction with $\mathrm{MAT}^{78}$ and are the only therapeutic opioids nationally approved for use on pregnant women battling addiction. ${ }^{79}$ The availability of treatments are expanding across the country in light of President Donald Trump's 2018 national budget, which includes an additional $\$ 500$ million to help states increase access to opioid treatment and recovery services. ${ }^{80}$

Methadone affects the same brain receptor sites as other opioids and sufficiently blocks the effects of opioid use, relieves opioid cravings, and reduces the symptoms associated with withdrawal. ${ }^{81}$ Methadone, used in Methadone Maintenance Therapy ("MMT"), has shown to be successful in treating opioid addiction when used as a long-term method. ${ }^{82}$ Studies also show that Methadone was a primary factor in curbing heroin addiction. ${ }^{83}$ Methadone use in heroin users was useful to "relieve narcotic craving, suppress the opioid abstinence syndrome for 24-36 hours, block the effects of administered heroin, develop tolerance to the euphoria, sedation or other narcotic effects of methadone which would impair

75. Id. at 7 .

76. Id.

77. Jessica Chiu et al., Romania: A Case Study in Using Policy Reform to Improve Access to Opioid Medicines, 24 TEMP. INT'L \& COMP. L.J. 389, 394-95 (2010).

78. Id. at 395.

79. Jeremiah A. Ho \& Alexander O. Rovzar, Preventing Neonatal Abstinence Syndrome Within the Opioid Epidemic: A Uniform Facilitative Policy, 54 HARV. J. on LegIs. 423, 433 (2017).

80. Office of Mgmt. \&Budget, America First:ABudget Blueprint to Make America GREAT AGAIN (2017), https://www.whitehouse.gov/sites/whitehouse.gov/files/omb/budget/ fy2018/2018_blueprint.pdf [perma.cc/H3M5-JXTJ].

81. Ho \& Rovzar, supra note 79 , at 434.

82. Id.

83. Herman Joseph et al., Methadone Maintenance Treatment (MMT): A Review of Historical and Clinical Issues, 67 Mount SinAi J. Med. 347, 351 (2000). 
emotional responses, functioning or perception, [and] develop tolerance to the analgesic properties of methadone." ${ }^{84}$ In short, "MMT has been celebrated as the most effective tool against heroin addiction." ${ }^{\prime 85}$

Buprenorphine is a similar treatment to methadone in that it prevents opioid abusers from experiencing withdrawal symptoms, but it is less likely to be abused than methadone. ${ }^{86}$ Since 2002, Suboxone and Subutex - two prescription drugs that contain buprenorphine - have been used to treat opioid addiction. ${ }^{87}$ Buprenorphine is used in a pill, film, or implant form, ${ }^{88}$ and research indicates that nearly fifty percent of those treated with buprenorphine for at least twelve weeks reduce prescription painkiller abuse. ${ }^{89}$

Buprenorphine, methadone, and Vivitrol are the three most commonly used medications in MAT, which combines the use of therapeutic opioids with counseling. ${ }^{90}$ MAT is regarded as the most effective treatment for opioid abuse, according to the U.S. Department of Health and Human Services. ${ }^{91}$ Through counseling and behavioral therapies, MAT aims to treat both the physical and mental aspects of a patient's addiction. ${ }^{92}$ Federal law requires individuals undergoing opioid treatment programs to also receive counseling. ${ }^{93}$ Studies have found that MAT has decreased heroin overdose deaths by as much as thirty-seven percent, decreased criminal activity and infectious disease transmission, increased social functioning, and decreased overall opioid abuse. ${ }^{94}$

84. Id. at 349 .

85. Jessica G. Katz, Herion Maintenance Treatment: Its Effectiveness and the Legislative Changes Necessary to Implement it in the U.S., 26 J. Contemp. HeAlth L. \& PoL'y 300, 305 (2010).

86. Barbara Andraka-Christou, America Needs The Treat Act: Expanding Access To Effective Medication For Treating Addiction, 26 Health Matrix 309, 321 (2016).

87. Alan Gordon \& Alexandra A. Gordon, Does it Fit? - A Look at Addiction, Buprenorphine, and the Legislation Trying to Make it Work, 12 J. HEALth \& BiomediCAL L. 1, 14 (2016).

88. Press Release, U.S. Food \& Drug Admin., FDA Approves First Buprenorphine Implant for Treatment of Opioid Dependence (May 26, 2016), https:/www.fda.gov/NewsEvents/ Newsroom/PressAnnouncements/ucm503719.htm [perma.cc/9MQA-LA6J].

89. Painkiller Abuse Treated by Sustained Buprenorphine/Naloxone, NAT'L Insts. HeALTH (Nov. 8, 2011), https://www.nih.gov/news-events/news-releases/painkiller-abuse-treated-sustainedbuprenorphine/naloxone [perma.cc/BST7-DEVN].

90. Andraka-Christou, supra note 86, at 188.

91. Opioid Abuse in the U.S. and HHS Actions to Address Opioid-Drug Related Overdoses and Deaths, U.S. Dep'T Health \& Hum. Servs. (Mar. 26, 2015), https://aspe.hhs.gov/basicreport/opioid-abuse-us-and-hhs-actions-address-opioid-drug-related-overdoses-and-deaths [perma.cc/KU62-PAQ6].

92. Medication and Counseling Treatment, Substance Abuse \& Mental Health Servs. ADMIN., https://www.samhsa.gov/medication-assisted-treatment/treatment [perma.cc/BFX7-F3NZ] (last updated Sept. 28, 2015).

93. Federal Opioid Treatment Standards, 42 C.F.R. $\S 8.12$ (2015).

94. Effective Treatment for Opioid Addiction, NAT'L InSt. DRUG ABUSE, https://www. 


\section{B. Naloxone: The Last Line of Defense}

Treatment programs are effective in helping to end an individual's dependency on opioids, but naloxone is available as a last defense when treatment has not worked on the patient. Because relapse during opioid abuse treatment programs does occur, ${ }^{95}$ it is important to have a safety net for individuals who overdose during a relapse so that they can have a 'next attempt' at recovery. In fact, naloxone offers that safety net to everybody and is effective "within 1-2 minutes of administration and last[s] 45 to 90 minutes. Opiate overdose reversal with naloxone is nearly universal, and adverse effects are rare at therapeutic doses. $" 96$

Traditionally, naloxone was administered by intravenous, intramuscular, or subcutaneous use at doses of $0.4 \mathrm{mg}$ to $2 \mathrm{mg}$ for an opioid overdose ${ }^{97}$ and was available in prefilled syringes and vials. ${ }^{98}$ In November 2015, the FDA approved Narcan Nasal Spray, giving people more comfort and ease to administer a noninjectable version of naloxone. ${ }^{99}$ Narcan advertises a quick, three-step process to administer its intranasal drug: Peel the film off the back of the package to open the device; place the tip of the nozzle into either nostril; and completely press the plunger to release the spray. ${ }^{100}$ The drug is safe and easy to use $\mathrm{e}^{101}$ and is available across the United States as a prescription medication. ${ }^{102}$ Naloxone is nonaddictive, ${ }^{103}$ and the FDA supports greater access to Narcan, ${ }^{104}$ in part because it

drugabuse.gov/publications/effective-treatments-opioid-addiction/effective-treatments-opioidaddiction [perma.cc/HUJ9-Z6MV] (last updated Nov. 2016).

95. George W. Joe et al., Treatment Process and Relapse to Opioid Use During Methadone Maintenance, 20 AM. J. Drug \& Alcohol ABuse 173, 173 (1994).

96. Phillip O. Coffin et al., Preliminary Evidence of Health Care Provider Support for Naloxone Prescription as Overdose Fatality Prevention Strategy in New York City, 80 J. URBAN Health 288, 288 (2003).

97. Joshua Lloyd, Clinical Team Leader, U.S. Food \& Drug Admin., The Clinical Use of Naloxone (July 1, 2015), https:/www.fda.gov/downloads/Drugs/NewsEvents/UCM454748.pdf [perma.cc/JGH2-EWK5].

98. U.S. Food \& Drug Admin., NAloxone for Treatment of Opioide Overdose (2016), https://www.fda.gov/downloads/AdvisoryCommittees/CommitteesMeetingMaterials/Drugs/Ane stheticAndAnalgesicDrugProductsAdvisoryCommittee/UCM522690.pdf [perma.cc/24TT-BHHD] [hereinafter NALOXONE FOR TREATMENT OF OPIOIDE OVERDOSE].

99. Id.

100. How To Use Narcan Nasal Spray, NARCAN, https:/www.narcan.com/patients/how-touse-narcan [perma.cc/9GB3-TE4K] (last visited Nov. 14, 2017).

101. Open Soc'y Founds., Intranasal Naloxone And Opioid Overdose (2012), https:/www.opensocietyfoundations.org/sites/default/files/intranasal-naloxone-04112012_1.pdf [perma.cc/JP5B-8VWW].

102. Narcan Nasal Spray Availability, NARCAN, https://www.narcan.com/availability [perma.cc/LP64-P3HK] (last visited Nov. 14, 2017).

103. Beletsky et al., Physicians' Knowledge of and Willingness to Prescribe Naloxone to 
"does not require assembly and delivers a consistent, measured dose when used as directed" and can easily be administered by non-medical professionals. ${ }^{105}$

Opioid overdose can be deadly in just a few minutes, so access to naloxone for those who are closest to the victims is imperative to successful intervention in overdose scenarios. ${ }^{106}$ Once administered, naloxone reverses the symptoms of an opioid overdose and provides relief for more than an hour, ${ }^{107}$ which gives the patient enough time to seek further medical help at an emergency room where medical personnel can observe the individual's response to naloxone and monitor for additional overdose symptoms. ${ }^{108}$ Individuals revived by naloxone have the option to not seek further medical care, and studies in Denmark show that those who refused transport to the hospital had just a 0.13 percent chance of having immediate "rebound opioid toxicity that likely led to death," 109 showing that even those who are unwillingly revived by naloxone still overwhelmingly survive the overdose. Side effects of naloxone stem from the underlying addiction and include agitation, body aches, dizziness, weakness, diarrhea, stomach pain, nausea, fever, chills, and sneezing - all common signs of opioid withdrawal. ${ }^{110}$

Indiana is increasing the number of people trained to administer naloxone, ${ }^{111}$ particularly in Indianapolis where Indianapolis Metropolitan Police Department officers and Indianapolis Fire Department staff receive training. ${ }^{112}$ From 2011 to 2015, naloxone use by Indianapolis Emergency Management Service personnel increased significantly and reversed nearly 4,000 opioid overdoses during that timeframe. ${ }^{113}$ The latest national statistics show that naloxone kits given to

Reverse Accidental Opiate Overdose: Challenges and Opportunities, 84 J. Urb. HeAlth 126, 127 (2007).

104. Karen Mahoney, FDA Supports Greater Access to Naloxone to Help Reduce Opioid Overdose Deaths, U.S. Food \& DRUG ADMIN. (Aug. 10, 2016), https://blogs.fda.gov/fdavoice/ index.php/2016/08/fda-supports-greater-access-to-naloxone-to-help-reduce-opioid-overdose-deaths/ [perma.cc/F33N-XEYX].

105. Press Release, U.S. Food \& Drug Admin., FDA Moves Quickly To Approve Easy-to-Use Nasal Spray to Treat Opioid Overdose (Nov. 18, 2015), https://www.fda.gov/NewsEvents/ Newsroom/PressAnnouncements/ucm473505.htm [perma.cc/P238-RZLB].

106. See Corey S. Davis et al., Engaging Law Enforcement in Overdose Reversal Initiatives: Authorization and Liability for Naloxone Administration, 105 AM. J. PuB. Health 1530, 1530 (2015).

107. Chamberlain \& Klein, supra note 21, at 651.

108. Bryan D. Hayes, 'Treat and Release' after Naloxone - What is the Risk of Death?, ACAD. LifE EMERGENCY MED. (Aug. 24, 2016), https://www.aliem.com/2016/08/treat-and-release-afternaloxone/ [perma.cc/J6KH-DDDC].

109. Id.

110. Naloxone, Substance Abuse \& Mental Health Servs. Admin., https://www.samhsa. gov/medication-assisted-treatment/treatment/naloxone [perma.cc/T2QV-Q33Q] (last updated Mar. 3, 2016).

111. DuWve ET AL., supra note 68 , at 80 .

112. Id. at 100 .

113. Id. at 99 . 
laypersons resulted in 26,463 overdose reversals from 1996 through June 2014. ${ }^{114}$

\section{Arguments Against the Availability of Naloxone}

Although many in medical and political fields see great usefulness in the expansion of naloxone availability, others see issues that arise when the overdose reversal drug is easily obtained. Among those concerns are the worry that expanding the availability of naloxone will provide opioid abusers an easy safety net from overdosing and will encourage and enable them to continue to take the drug at dangerous levels; ${ }^{115}$ the cost associated with naloxone administration; ${ }^{116}$ the safety of patients when naloxone is administrated by unlicensed persons; $;{ }^{117}$ and the unwillingness of some doctors to treat drug abusers because of the social stigma that comes along with the treatment, thus leaving some drug abusers with access to naloxone but no real rehabilitation treatment that leads to a path of recovery. ${ }^{118}$

A common argument against expanding the availability of naloxone is the perception that individuals can abuse the drug by using it as a quick antidote to an overdose, which merely sustains their habit. In 2016, Maine Governor Paul LePage vetoed a bill that would allow the distribution of naloxone without a prescription for that very reason. In his veto letter sent to the state's congress, LePage wrote:

Naloxone does not truly save lives; it merely extends them until the next overdose. Creating a situation where an addict has a heroin needle in one hand and a shot of naloxone in the other produces a sense of normalcy and security around heroin use that serves only to perpetuate the cycle of addiction. ${ }^{119}$

One dissenter to LePage's outlook, Maine state senator Cathy Breen, called the Governor's statement "insensitive" and explained that "Narcan can be the difference between an early grave and an intervention that can put an addict on the path to recovery." 20 Breen's sentiment is shared by many, and "studies addressing this argument suggest that the increase in overdose awareness via opioid overdose training programs reduces opioid use and increases a drug user's

114. Eliza Wheeler et al., Opioid Overdose Prevention Programs Providing Naloxone to Laypersons - United States, 2014, CTRS. FOR Disease Control \& Prevention (June 19, 2015), https://www.cdc.gov/mmwr/preview/mmwrhtml/mm6423a2.htm [perma.cc/RP6M-VURT].

115. Kevin Miller, LePage Vetoes Bill Aimed at Increasing Access to Overdose Antidote, Portland PRESS HERALD (Apr. 20, 2016), http://www.pressherald.com/2016/04/20/lepage-vetoesbill-aimed-at-increasing-access-to-heroin-anti-overdose-drug/ [perma.cc/F8EB-LFSA].

116. Jonathan S. Miller, Increasing Access to Naloxone: Overcoming Societal Challenges to Reduce Opioid Overdose Fatalities, 26 ALB. L.J. SCI. \& TECH. 77, 96 (2016).

117. Id. at 95 .

118. Beletsky et al., supra note 103, at 127.

119. Miller, supra note 115.

120. Id. 
desire to seek treatment."121 Further, naloxone causes similar, and even stronger, unpleasant symptoms that opioid abusers are trying to counteract, making them unlikely to be "more comfortable using heroin frequently or in higher doses because of naloxone availability." 122

Treatment with naloxone is most effective when done together with counseling or therapy, ${ }^{123}$ but social stigma exists among health professionals who treat drug abusers, leading to many patients receiving inadequate care. ${ }^{124}$ The perception of medical professionals treating drug abusers "may reflect the widespread social perception that drug abuse is a self-inflicted behavior, less worthy of clinical care and treatment." ${ }^{25}$ Doctors also may not be properly informed of the laws surrounding naloxone and may inadequately understand the "realm of substance abuse." 26 There exists a concern that easy access to naloxone paired with inadequate rehabilitation therapy and professional medical assistance acts as a barrier to actual recovery. But educating medical professionals of legal concerns, the nuances of treating a drug abuser, and the efficiency of treatment options for opioid addiction alleviates those worries by giving physicians more confidence to treat patients battling drug addiction. ${ }^{127}$

When a layperson administers naloxone, safety becomes a common concern for both recipients and administrators of the drug. Many laypersons are concerned about both the liability of administering the drug ${ }^{128}$ and their immediate safety because of the possibility of a revived patient becoming agitated and potentially violent. ${ }^{129}$ Safety of administrators, however, is becoming less of an issue with the advent of intranasal naloxone administration, with studies showing that patients who received intranasal administration were substantially less likely to become agitated than those who received intramuscular administration. ${ }^{130}$ In fact, there is evidence that the use of naloxone actually limits potential injury to a bystander because there is no need for a limp patient to be carried a long distance to

121. Miller, supra note 116, at 95-96.

122. Daniel Kim et al., Expanded Access to Naloxone: Options for Critical Response to the Epidemic of Opioid Overdose Mortality, 99 Am. J. Pub. Health, 402, 404 (2009).

123. See Medication and Counseling Treatment, supra note 92.

124. Leonieke C. Van Boekel et al., Stigma Among Health Professionals Towards Patients with Substance Use Disorders and its Consequences for Healthcare Delivery: Systematic Review, 131 Drug \& Alcohol Dependence 23, 23 (2013).

125. Beletsky et al., supra note 103, at 127.

126. Id. at 132 .

127. Id. at 134.

128. See Karl A. Sporer \& Alex H. Kral, Prescription Naloxone: A Novel Approach to Heroin Overdose Prevention, 49 ANNALs EMERGENCY MED. 172, 173 (2007).

129. Daniel P. Wermeling, Review of Naloxone Safety for Opioid Overdose: Practical Considerations for New Technology and Expanded Public Access, 6 Therapeutic Advances Drug SAFety 20, 21 (2015).

130. Maya Doe-Simkins et al., Saved by the Nose: Bystander-Administered Intranasal Naloxone Hydrochloride for Opioid Overdose, 99 Aм. J. PuB. HeAlth 788, 791 (2009). 
awaiting first responders if they have been revived successfully. ${ }^{131}$ Inexperienced administrators - both bystanders and drug users themselves - also carry concerns that they will improperly administer naloxone,${ }^{132}$ but anyone can be easily trained to administer the drug in a safe and proper manner. ${ }^{133}$

A final concern in making naloxone more available is the cost associated with distributing the drug. ${ }^{134}$ The cost of naloxone is inflated by its status as a prescription drug and by the FDA labeling it as an injected medicine, ${ }^{135}$ but it still remains relatively inexpensive, ranging from $\$ 15$ to $\$ 30$ for a naloxone kit. ${ }^{136}$ Furthermore, naloxone distribution was proven cost-effective when given to heroin users by limiting the number of overdoses and cutting back on the use of emergency medical services. ${ }^{137}$

\section{NALOXONE AND THE LAW}

\section{A. How Indiana Treats Naloxone}

Indiana is among the states with the least restrictive naloxone laws, ${ }^{138}$ but there are still steps the Indiana legislature can take to remove even more barriers to naloxone access. The legislature took its biggest step toward greater naloxone availability in 2015 when it passed "Aaron's Law," the state's first attempt to make the overdose reversal drug more accessible to the public. ${ }^{139}$ "Aaron's Law" allows a prescriber to prescribe or dispense naloxone without examining the individual if the individual is at risk of an opioid overdose or knows somebody who is at risk of an opioid overdose, thus making the overdose reversal drug available to virtually anybody in the state. ${ }^{140}$ The law, however, still requires an individual to receive a prescription from a prescriber, which is an unnecessary restriction on access to the crucial drug. Prescriber is defined in Section 16-4227-1 of the Indiana Code as a licensed physician, a licensed physician's assistant

131. Mike McEvoy, Why Intranasal Naloxone is a Safe Antidote for Anyone to Administer, EMS1 (May 31, 2014), https://www.ems1.com/drugs/articles/1922308-Why-intranasal-naloxone-isa-safe-antidote-for-anyone-to-administer/ [perma.cc/B595-3J93].

132. Miller, supra note 116 , at 95.

133. McEvoy, supra note 131.

134. Miller, supra note 116 , at 96.

135. Scott Burris et al., Stopping an Invisible Epidemic: Legal Issues in the Provision of Naloxone to Prevent Opioid Overdose, 1 DreXEL L. REV. 273, 278 (2009).

136. Phillip O. Coffin \& Sean D. Sullivan, Cost-Effectiveness of Distributing Naloxone to Heroin Users for Lay Overdose Reversal, 158 AnNALS OF INTERNAL MED. 1, 3 (2013).

137. Id. at 1 .

138. Naloxone Overdose Prevention Laws, LEGAL SCI., http://pdaps.org/datasets/lawsregulating-administration-of-naloxone-1501695139 [perma.cc/JG5E-QS4F] (last updated July 1, 2017).

139. Naloxone and Aaron's Law: Frequently Asked Questions, Ind. St. Dep't Health, https:/optin.in.gov/faq.html [perma.cc/F483-EYE3] (last visited Jan. 2, 2018).

140. IND. CODE $\S 16-42-27-2$ (2017). 
under the supervision of a physician, an advanced practice nurse licensed to prescribe drugs, the state health commissioner, or a public health authority. ${ }^{141}$

"Aaron's Law" necessitates the prescriber to take further steps, including requirements that:

(2) The prescriber instructs the individual receiving the overdose intervention drug or prescription to summon emergency services either immediately before or immediately after administering the overdose intervention drug to an individual experiencing an opioid-related overdose; (3) The prescriber provides education and training on drug overdose response and treatment, including the administration of an overdose intervention drug; [and] (4) The prescriber provides drug addiction treatment information and referrals to drug treatment programs, including programs in the local area and programs that offer medication assisted treatment that includes a federal Food and Drug Administration approved long acting, nonaddictive medication for the treatment of opioid or alcohol dependence. ${ }^{142}$

"Aaron's Law" was amended in 2016 to allow some individuals and entities to receive a statewide standing order to dispense naloxone to individuals without a prescription. ${ }^{143}$ Even though naloxone is still considered a prescription drug in the United States, the amendment allows pharmacies or other non-profit organizations or individuals, defined by the Indiana State Department of Health as "Naloxone Entities," to obtain a year-by-year standing order from a prescriber to dispense naloxone to anybody who is at risk of an opioid-related overdose. ${ }^{144}$ The law requires Naloxone Entities to follow several criteria in order to qualify for and retain the standing order, including:

(1) Obtain naloxone from a prescriber (physician, physician assistant or advanced practice nurse with authority to prescribe) either by virtue of the attached standing order or other standing order or prescription issued by a prescriber; (2) Annually register as a Naloxone Entity at https://optin.in.gov/ in a manner prescribed by the Indiana State Department of Health ("ISDH"); (3) Provide education and training on drug overdose response and treatment, including the administration of an overdose intervention drug and the legal requirement to call 9-1-1 immediately before or after administering the drug; and (4) Provide drug addiction treatment information and referrals to drug treatment programs, including programs in the local area and programs that offer medication

141. Id. $\S 16-42-27-1$.

142. Id. $\S 16-42-27-2$.

143. Naloxone and Aaron's Law: Frequently Asked Questions, supra note 139.

144. Indiana Statewide Naloxone Standing Order Toolkitfor Naloxone Entities, IND. ST.DeP'T HEALth, https://optin.in.gov/files/Indiana-Statewide-Naloxone-Standing-Order-Toolkit.pdf [perma.cc/E2Z2-HHY2] (last visited Jan. 2, 2018). 
assisted treatment that includes a federal Food and Drug Administration approved long acting, non-addictive medication for the treatment of opioid or alcohol dependence. ${ }^{145}$

The list of Naloxone Entities in Indiana is ever-expanding and includes many major pharmacy chains, schools, and local health departments. ${ }^{146}$ As of July 1, 2017 - when Indiana State Health Commissioner Jerome M. Adams renewed the statewide standing order-nearly 500 locations were listed as Naloxone Entities. ${ }^{147}$

Additionally, in Indiana an individual cannot be taken into custody by law enforcement for possession of cocaine, methamphetamine, a controlled substance, paraphernalia, marijuana, or a synthetic drug if the individual solely "came into contact with law enforcement because the individual requested emergency medical assistance for another individual who appeared to be experiencing an opioid-related overdose," among other requirements. ${ }^{148}$ Section 16-42-27-3 of the Indiana Code also provides immunity from civil liability to prescribers, pharmacists, and Naloxone Entities for their involvement with naloxone, except in acts of gross negligence or willful misconduct. ${ }^{149}$

\section{B. Naloxone Laws Around the Country}

Jurisdictions throughout the United States have varying degrees of laws governing the use of naloxone. ${ }^{150}$ Although Naloxone is still classified as a prescription drug by the FDA, ${ }^{151}$ most states, like Indiana, have found a workaround by issuing a standing order to medical professionals that allows them to dispense naloxone to individuals who do not have a prescription from a physician. At least thirty-four states have passed laws allowing pharmacists to dispense naloxone without a prescription, ${ }^{152}$ while other states have passed laws to provide immunity to prescribers, dispensers, administrators, and those who summon emergency responders to the scene of an overdose. ${ }^{153}$ All but three states

145. Id.

146. See Find Naloxone Entity, Ind. St. DeP'T HeAlth, https://optin.in.gov/search.html [perma.cc/VUF7-NR4J] (last visited Jan. 2, 2018).

147. Press Release, Ind. St. of Dep't Health, State Health Commissioner Renews Naloxone Standing Order (June 30, 2017), https://calendar.in.gov/site/isdh/event/state-health-commissionerrenews-naloxone-standing-order/ [perma.cc/RQ6B-6G6R].

148. IND. CODE $§ 16-42-27-2$ (2017).

149. Id. § 16-42-27-3.

150. See Naloxone Overdose Prevention Laws, supra note 138.

151. Mahoney, supra note 104.

152. Debra Miller, Opioid Overdose Protection, CouncIL ST. Gov'T (June 20, 2015), $\mathrm{http}$ //knowledgecenter.csg.org/kc/content/opioid-overdose-protection-note [perma.cc/3EXERWFE].

153. Corey S. Davis \& Derek H. Carr, The Law and Policy of Opioids for Pain Management, Addiction Treatment, and Overdose Reversal, 14 InD. HeAlth L. Rev. 1, 30 (2017). 
have passed laws addressing naloxone distribution or prescribing. ${ }^{154}$

Indiana provides both prescribers and dispensers immunity from civil liability for prescribing, dispensing, or distributing naloxone to a layperson but does not offer immunity from criminal liability or professional sanctions. ${ }^{155}$ Most states offer immunity from civil liability, criminal liability, and professional sanctions, ${ }^{156}$ leaving Indiana behind the rest of the country in incentivizing medical professionals to distribute naloxone. For prescribers, thirty-seven states offer criminal liability immunity, forty-one offer civil liability immunity, and thirty-five offer immunity from professional sanctions. ${ }^{157}$ For dispensers, thirtysix states offer criminal liability immunity, forty-one offer civil liability immunity, and thirty-five offer immunity from professional sanctions. ${ }^{158}$

Indiana is also one of thirteen states that does not offer laypersons immunity from criminal liability when administering naloxone. ${ }^{159}$ Only five states-Ohio, South Dakota, Nebraska, Oklahoma, and Delaware - do not have laws that give a layperson immunity from civil liability when administering naloxone. ${ }^{160}$

\section{WAYS TO ENCOURAGE ACCESS TO NALOXONE}

\section{A. Immunity from Criminal Liability and Professional Sanctions for Prescribers and Dispensers of Naloxone}

South Carolina is one of twenty-seven states that provide immunity from criminal liability, civil liability, and professional sanctions for both prescribers and dispensers ${ }^{161}$ - in 2015, the state's legislature passed the South Carolina Overdose Prevention Act. ${ }^{162}$ In the year after the bill was signed into law, naloxone use in South Carolina jumped by 39.7 percent, giving more people around the state access to the life-saving drug. ${ }^{163}$

Experts emphasize the importance of immunity for prescribers and dispensers because "fear of legal consequences can cause some clinicians to be wary of prescribing and dispensing the medication." ${ }^{.64}$ While naloxone is overwhelmingly

154. Id.

155. Naloxone Overdose Prevention Laws, supra note 138.

156. Id.

157. Id.

158. Id.

159. Id.

160. Id.

161. Id.

162. Joseph Y. Shenkar, Back from The Dead: A Breath of Hope for South Carolina, S.C. LAW., Mar. 2017, at 30, 32.

163. Gregory Yee, Narcan Use On The Rise In South Carolina Amid Ongoing Opioid Epidemic, Charleston POst \& COURIER (Jan. 29, 2017), https://www.postandcourier.com/ news/narcan-use-on-the-rise-in-south-carolina-amid-ongoing/article_212301b2-d784-11e6-9e85c3d1d8b9bf5a.html [perma.cc/K45Z-SDHL].

164. Corey S. Davis \& Derek H. Carr, Legal Changes To Increase Access To Naloxone For 
safe to administer, a study showed that just over one percent of patients treated with the drug suffered either cardiorespiratory complications or seizures. ${ }^{165}$ This risk of liability - or at least the fear of it, warranted or not-for doctors and pharmacists should persuade the Indiana legislature to consider passing laws that eliminate those concerns while naloxone is still a prescription drug.

A 2015 study found no cases of a prescriber or distributor facing legal consequences due to participation in community distribution programs, which have treated more than 10,000 individuals with naloxone. ${ }^{166}$ Of civil liability, criminal liability, and professional sanctions, criminal liability is least likely to affect a physician or pharmacist who prescribe or dispense naloxone, "but to address the concerns of some practitioners most of these laws also provide immunity from criminal sanction[s]." ${ }^{\prime 67}$ Doctors likely carry this misguided fear of criminal liability because of inadequate instruction about substance abuse during medical school and residency. ${ }^{168}$ And aside from improving medical education of substance abuse, the easiest way for a state legislature to ease concerns in this area is to eliminate the possibility of criminal liability as long as a medical professional acts in good faith, which is already a condition for receiving immunity from civil liability. ${ }^{169}$ This would mirror the Illinois law that protects health care professionals from criminal liability - a statute that says any health care professional acting in good faith who prescribes or dispenses naloxone is not subject to criminal liability unless there is willful or wanton misconduct. ${ }^{170}$

But this legislative solution does not simply stop at passing a law. Pharmacists around the country have been reluctant to dispense naloxone despite laws that eliminate liability and treat the drug as an over-the-counter medication, ${ }^{171}$ and that apprehension was addressed during a recent meeting of the American Pharmacists Association ("APA"). ${ }^{172}$ Many pharmacists are unaware of laws that protect them from criminal liability for dispensing naloxone, so when a state passes immunity laws, pharmacists must be educated and aware of the legislation for it to be effective, said Christopher Herndon, associate professor in

Opioid Overdose Reversal In The United States, 157 Drug \& Alcohol Dependence 112, 115 (2015).

165. NALOXONe For TREATMEnt OF Opioide Overdose, supra note 98.

166. Davis et al., supra note 106, at 1531.

167. Davis \& Carr, supra note 164 , at 116.

168. Beletsky et al., supra note 103, at 132-33.

169. IND. CODE $§ 16-42-27-3$ (2017).

170. 20 Ill. Comp. StAT. $\S 301 / 5-23$ (2017).

171. Anna Gorman, Pharmacists Slow To Dispense Lifesaving Overdose Drug, WASH. Post (Jan. 3, 2018), https://www.washingtonpost.com/national/health-science/pharmacists-slow-todispense-lifesaving-overdose-drug/2018/01/03/0628c8e2-f06f-1 1 e 7-95e3eff284e71c8d_story.html?noredirect $=$ on\&utm_term $=.21 \mathrm{e} 3 \mathrm{ccd} 5 \mathrm{~b} 2 \mathrm{e} 0$ [perma.cc/5QWA-QQ8E].

172. Valerie DeBenedette, Naloxone: Liability, Regulatory Concerns for Pharmacists, DRUG TOPICS (July 10, 2016), http://drugtopics.modernmedicine.com/drug-topics/news/naloxoneliability-regulatory-concerns-pharmacists [perma.cc/2UNX-TZ8H]. 
the Department of Pharmacy Practice at Southern Illinois University, Edwardsville, School of Pharmacy. ${ }^{173}$ Overdose education and naloxone distribution ("OEND") teams have developed recommendations for prescribing and dispensing naloxone, and giving background information of the drug and educating health care professionals of related state laws are included in the OEND's guidelines. ${ }^{174}$

Indiana's statewide standing order to dispense naloxone to individuals without a prescription already requires pharmacists to provide recipients of naloxone with information on drug addiction and naloxone administration, ${ }^{175}$ and toolkits advising pharmacists of this requirement are distributed by the Indiana State Department of Health. ${ }^{176}$ But there is currently no language in the toolkit that advises pharmacists of their immunity from civil liability in dispensing naloxone. ${ }^{177}$ Including information of applicable laws - such as any new law eliminating criminal liability when acting in good faith - is a practical and simple way to make sure each pharmacist in the state is aware of the legality of naloxone dispensing, which complies with the OEND's suggestions.

Prescribers and dispensers have similar concerns over possible professional sanctions that could surface from naloxone participation. ${ }^{178}$ In Indiana, the medical licensing board has the authority to discipline a physician, ${ }^{179}$ and sanctions range from placing a practitioner on probation to permanently revoking a practitioner's license. ${ }^{180}$ Similarly, Indiana pharmacists are subject to discipline by the board of pharmacy, ${ }^{181}$ which can levy penalties for various forms of misconduct, such as "negligence or gross misconduct in providing home medical equipment services." "182 Twenty-eight states offer immunity from professional sanctions to either physicians or pharmacists. ${ }^{183}$ There is evidence that malpractice liability concerns make some medical professionals reluctant to deal with naloxone. ${ }^{184}$ Prescribers and dispensers under Indiana's statewide naloxone standing order can still only issue naloxone to a patient who is either at risk of an overdose or who is in position to assist an individual who is at risk for an overdose $^{185}$ - the latter of which "would amount to deputizing the lay person as

173. Id.

174. Jennifer Devries, Implementing an Overdose Education and Naloxone Distribution Program in a Health System, 57 J. Am. PhaRmacists Ass'N S154, S156 (2017).

175. IND. CODE $§ 16-42-27-2$ (2017).

176. Indiana Statewide Naloxone Standing Order Toolkit for Naloxone Entities, supra note 144.

177. Id.

178. Beletsky et al., supra note 103, at 133.

179. IND. CODE $\S 25-1-5-4$.

180. Id. § 25-1-9-9.

181. Id. § 25-26-13-4.

182. Id. $\S 25-26-21-10$.

183. Naloxone Overdose Prevention Laws, supra note 138.

184. Beletsky et al., supra note 103, at 133.

185. IND. CODE $§ 16-42-27-2$. 
a medical practitioner" and open the door for a licensed professional to be subject to charges of professional misconduct. ${ }^{186}$ An effective way to ease those concerns and encourage naloxone availability is by "removing the possibility that medical professionals who prescribe the drug ... will face legal or regulatory sanction for doing so." "187

\section{B. Immunity from Criminal Liability for Laypersons in the Administration of Naloxone}

The National Alliance for Model State Drug Laws defines layperson immunity as "[a] person who does not have professional or specialized knowledge in dispensing, distributing, or administering naloxone or other opioid antagonist will not be held liable to someone who is overdosing, if that person administers naloxone or other opioid antagonist to the person suffering from the overdose." 188 Although Indiana offers criminal immunity from certain drug possession offenses to laypersons who administer naloxone to an overdose victim and remain at the scene until first responders arrive, ${ }^{189}$ third party administers of naloxone are not protected against any other prosecution related to the administration of the drug. This is in contrast with the majority of other states, ${ }^{190}$ such as Rhode Island, which provides that "[a] person who administers an opioid antagonist to another person pursuant to this section shall not be subject to civil liability or criminal prosecution as a result of the administration of the drug." 191 West Virginia further explains its immunity for laypersons - often called Good Samaritan laws - in the following statute, which protects third parties from actions or a failure to act when in possession of naloxone. ${ }^{192}$

"Any person who possesses an opioid antagonist and administers it to a person whom they believe to be suffering from an opioid-related overdose and who is acting in good faith is not, as a result of his or her actions or omissions, subject to criminal prosecution arising from the possession of an opioid antagonist or subject to any civil liability with respect to the administration of or failure to administer the opioid antagonist unless the act or failure to act was the result of gross negligence or willful misconduct." ${ }^{193}$

186. Burris et al., supra note 135, at 311-12.

187. Corey Davis et al., Changing Law from Barrier to Facilitator of Opioid Overdose Prevention, 41 J.L. MED. \& ETHICs 33, 34 (2013).

188. Nat'L All. for Model State Drug Laws, Naloxone Access Statutes (2014), http://www.namsdl.org/library/16CE4FDC-19B9-E1C5-3175B29881A03FBC/ [perma.cc/MF5KJNZW].

189. IND. CODE $§ 16-42-27-2$.

190. Naloxone Overdose Prevention Laws, supra note 138 (showing that Indiana is one of just 13 states where a layperson is not immune from criminal liability while administering naloxone).

191. 21 R.I. GEN. LAWS $\S 21-28.9-3$ (2017).

192. W. VA. CODE, § 16-46-5 (2017).

193. Id. 
Good Samaritan laws "have few if any foreseeable negative effects," 194 and can offer protection from a wide range of criminal liabilities, including violation of a protective or restraining order, ${ }^{195}$ violation of pretrial probation or parole,${ }^{196}$ and underage alcohol consumption. ${ }^{197}$ In addition, "there are liability concerns about administering the medication as a bystander" that can be erased by offering immunity to laypersons. ${ }^{198}$

Through data collected by the Harm Reduction Coalition, it is apparent that naloxone in the hands of laypersons significantly reduces opioid overdose mortality. ${ }^{199}$ Protecting the interests of laypersons during the administration of naloxone is vital because laypersons are often first on the scene of an overdose and provide the best opportunity to save the victim when time is of the essence, ${ }^{200}$ and because of the wide availability of naloxone kits through Indiana's standing order ${ }^{201}$ more laypersons than ever will have their hands on the drug and be subject to possible criminal prosecution.

\section{Making Naloxone an Over-The-Counter Medication}

One of the biggest hindrances to the expansion of naloxone use in the United States is its qualification as a prescription drug $^{202}$ - the reversal of which removes the need for prescriber and dispenser immunity.

Countries around the globe are moving in the direction of rescheduling naloxone as an over-the-counter drug, a trend that hit close to home in 2016 when Canada removed naloxone from the Prescription Drug List ${ }^{203}$ joining countries

194. The Network for Pub. Health, Legal Interventions to Reduce Overdose Mortality: Naloxone Access ANd Overdose Good SAmaritan Laws (2017), https://www.networkforphl.org/_asset/qz5pvn/network-naloxone-10-4.pdf[perma.cc/R62C-G7GH].

195. ARK. Code ANn. § 20-13-1704 (2017).

196. D.C. Code $\S 7-403$ (2017).

197. Del. Code AnN. tit. $16 \S 4769$ (2017).

198. Allison Muller, Naloxone: The Science and Laws Behind the Antidote, AM. BAR Ass'N, $\mathrm{https}$ ://www.americanbar.org/publications/aba_health_esource/2016-2017/opioids/naloxone.html [perma.cc/3QA4-JZE8] (last visited Jan. 25, 2018).

199. Eliza Wheeler et al., Opioid Overdose Prevention Programs Providing Naloxone to Laypersons - United States, 2014, 64 Morbidity \& MorTALITY WKLy. ReP. 631, 631 (June 19, 2015) (showing that, "[f]rom 1996 through June 2014, surveyed organizations provided naloxone kits to 152,283 laypersons and received reports of 26,463 overdose reversals").

200. Davis \& Carr, supra note 153, at 28.

201. Indiana Statewide Naloxone Standing Order Toolkit for Naloxone Entities, supra note 144.

202. FDA Approved Drug Products, U.S. Food \& DRUG AdmIN., https://www.accessdata. fda.gov/scripts/cder/daf/index.cfm?event=overview.process\&ApplNo=070299 [perma.cc/P5ZZ78CJ] (last visited Jan. 25, 2018).

203. Can. Ctr. on Substance Abuse, The Availability of Take-Home Naloxone in CANADA (2016), http://www.ccsa.ca/Resource\%20Library/CCSA-CCENDU-Take-HomeNaloxone-Canada-2016-en.pdf [perma.cc/L97U-VE2G]. 
like Italy ${ }^{204}$ and Australia. ${ }^{205}$ In the United States, drugs that are available as prescription medications can be rescheduled as over-the-counter if the FDA commissioner determines that the prescription is:

Not necessary for the protection of the public health by reason of the drug's toxicity or other potentiality for harmful effect, or the method of its use, or the collateral measures necessary to its use, and he finds that the drug is safe and effective for use in self-medication as directed in proposed labeling. ${ }^{206}$

Since it has already been established that naloxone has no potential for abuse, ${ }^{207}$ the FDA's decision to reschedule the drug would likely depend "on data showing that the consumer can safely and effectively use the device without interaction with a medical professional, as well as read and understand the label." ${ }^{208}$ If the federal government does not reschedule naloxone as an over-thecounter drug, Indiana can pass legislation that removes criminal liability for possession of naloxone without a prescription - a law that is already approved in fifteen states. ${ }^{209}$ Statistics show that "removing criminal liability for possession of naloxone is associated with a 13 percent reduction in opioid-related deaths." 210

Although Indiana has functionally made naloxone an over-the-counter medication by stripping the necessity of a prescription at participating Naloxone Entities around the state, ${ }^{211}$ there are still individuals throughout the state that are restricted by naloxone's characterization as a prescription drug because of a lack of access to Naloxone Entities. ${ }^{212}$ Of the ninety-two Indiana counties, twentyseven house fewer than three Naloxone Entities. ${ }^{213}$ LeGrange, Tipton, Martin, Brown, Pike, and Spencer counties have just one Naloxone Entity apiece, and Benton, Warren, Crawford, and Ohio counties contain zero Naloxone Entities. ${ }^{214}$ In the ten Indiana counties that have fewer than two Naloxone Entities, twentyone opioid overdoses were fatal from 2011 to $2015^{215}$ - twenty-one deaths that

204. Coffin et al., supra note 96, at 288.

205. Davis \& Carr, supra note 153 , at 34.

206. Prescription-exemption procedure for drugs limited by a new drug application, 21 C.F.R. $\S 310.200$ (b) (2017).

207. Naloxone for Treatment of Opioide Overdose, supra note 98.

208. Davis \& Carr, supra note 153 , at 37.

209. Naloxone Overdose Prevention Laws, supra note 138.

210. Daniel I. Rees et al., With a Little Help from My Friends: The Effects of Naloxone Access and Good Samaritan Laws on Opioid-Related Deaths 1-2 (Nat'l Bureau of Econ. Research, Working Paper No. 23171, 2017).

211. Indiana Statewide Naloxone Standing Order Toolkit for Naloxone Entities, supra note 144.

212. Find Naloxone Entity, supra note 146 (showing that many rural areas of Indiana are without Naloxone Entities).

213. $I d$.

214. Id.

215. Ind. State Dep't of Health, County Profiles of Opioid Use and Related 
could have been prevented by the administration of naloxone. Other states around the country that do not have laws that parallel Indiana's standing order would benefit even more from the federal government reclassifying naloxone as an overthe-counter drug. ${ }^{216}$

In addition, over-the-counter reclassification is crucial due to some doctors' reluctance to prescribe naloxone. ${ }^{217}$ Due to negative attitudes toward drug users, fear of professional disapproval, and pessimism in treating drug use, fifty-four percent of responding physicians in a nation-wide survey said they would never even consider prescribing naloxone, while twenty-three percent said they had never heard of the drug. ${ }^{218}$ Rescheduling naloxone as over-the-counter not only makes the life-saving drug accessible to individuals unable to obtain a prescription due to limited contact with a naloxone distribution center and doctors' unfamiliarity with the drug, but it also makes it available to people without health insurance or those fearful of being judged by a medical professional when asking for a naloxone prescription. ${ }^{219}$

\section{CONCLUSION}

Opioid abuse and overdose is a prevailing problem sweeping across the United States, and the crisis hits hard in Indiana, where hundreds die each year because of an addiction to opioids. ${ }^{220}$ There are many treatment options available to those willing to overcome their addiction, but when the treatment fails or momentarily lapses, naloxone is available to reverse the effects of an overdose and preserve the life of the individual. ${ }^{221}$ Within the past few years, advances in naloxone administering tools, specifically through intranasal use, have allowed the drug to be used more abundantly. ${ }^{222}$

This Note argued that there should be minimal restrictions on the access to naloxone, and practical ways to encourage the use of the life-saving drug include passing laws that provide criminal and professional immunity to prescribers, dispensers, and laypersons and permitting naloxone to be purchased as an overthe-counter drug. This conclusion is supported by the sentiment of those in the

Outcomes (2017), https:/www.in.gov/isdh/files/CountyProfilesOfOpioidUse2017.pdf [perma.cc/8V2E-LACM].

216. Davis \& Carr, supra note 153 , at 34.

217. Beletsky et al., supra note 103, at 132 .

218. Id.

219. Megan McLemore \& Corey Davis, A Simple Move to Save Thousands of Lives From Overdose, N.Y. Times (Aug. 18, 2017), https://www.nytimes.com/2017/08/18/opinion/overdosenaloxone-opioids-trump.html [perma.cc/P6J4-Y46S].

220. INDIANA BY THE NumBers, supra note 8.

221. Coffin et al., supra note 96 , at 288.

222. NALOXONE FOR TREATMENT OF Opioide Overdose, supra note 98. 
medical community that believe naloxone access should be encouraged, a view shared by the FDA. ${ }^{223}$ Furthermore, states and other countries that have passed immunity laws and legalized naloxone as an over-the-counter drug have been successful in treating opioid overdoses. ${ }^{224}$

223. Mahoney, supra note 104.

224. Coffin et al., supra note 96, at 288 (showing that no adverse effects were recorded with increased naloxone availability in Italy, Germany, and the United Kingdom); Yee, supra note 163 (showing that in the year after the South Carolina Overdose Prevention Act was signed into law, naloxone use in South Carolina jumped by 39.7 percent). 